\begin{tabular}{|c|c|}
\hline \multirow{3}{*}{ 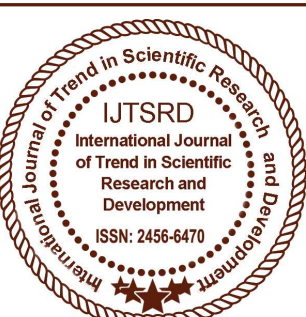 } & $\begin{array}{l}\text { International Journal of Trend in Scientific } \\
\text { Research and Development (IJTSRD) }\end{array}$ \\
\hline & International Open Access Journal \\
\hline & ISSN No: 2456 - 6470 | www.ijtsrd.com | Volume - 2 | Issue -3 \\
\hline
\end{tabular}

\title{
Implementation of Functional Analysis using Value Analysis Value Engineering (Vave) on Car Outside Handle
}

\author{
Samudra Shant Kumar, Chirag V. Mali, Harsh Vinay Kshirsagar, Prof. Shital Patel \\ Bharati Vidyapeeth College of Engineering, Navi Mumbai, Maharashtra, India
}

\section{ABSTRACT}

This paper presents one of the tools used in Value Analysis Value Engineering (VAVE) methodology; Functional Analysis and its implementation during New Product Development (NPD) phase. Current vehicle outer door handle has been redesigned through its functions in order to meet customer requirements of having higher value vehicle, by increasing performance while trying to decrease the cost without scarifying the quality, sale ability and maintainability. An analysis has been made and discussed using Function Analysis System Technique (FAST) diagram to achieve product optimization. Finally, results obtained are discussed.

Keywords: functional analysis, value analysis (VA), value engineering (VE), new product development (NPD), FAST diagram.

\section{INTRODUCTION}

Functional Analysis is a fundamental tool of the design process to explore new concepts and define their architectures. When systems engineers design new products, they perform Functional Analysis to refine the new product's functional requirements, to map its functions to physical components, to guarantee that all necessary components are listed and that no unnecessary components are requested and to understand the relationships between the new product's components. The conceptual design stage in NPD phase is where the role of Functional Analysis is highlighted.

\section{THE JOB PLAN}

Value engineering is often one by systematically following a multistage job plan.

Lary Miles 'original system was a six step procedure which he called the" value analysis job plan." Others have varied the job plant of it their constraints. Depending on the application, there maybe four, five, six, or more stages. One modern version has the following eight steps:

1.) Preparation

2.) Information

3.) Analysis

4.) Creation

5.) Evaluation

6.) Development

7.) Presentation

8.) Follow-Up

VALUE ANALYSIS

\section{MANUFACTURING:}

\section{Methodology of Value Engineering}

Systematic analysis that identifies and selects the best value alternatives for designs ,materials, processes, and systems. It proceeds by repeatedly asking "can the cost of this it emor Step be reduced or eliminated, without diminishing the effectiveness, required quality, or customer satisfaction?" Also called value engineering, its objectives are to distinguish between the incurred costs(actual use of resources) and the 
costs inherent (locked in) in a particular design (and which determine the incurring costs), and to minimize the locked -in costs.

\section{PURCHASING:}

Examination of each procurement it to as certainits total cost of acquisition, maintenance, and usage over its useful if And, wherever feasible, to replace it with a more cost-effective substitute.

In value analysis Functions may be broken down into a hierarchy, starting with a basic function, for which the customer believes they are paying, and then followed by secondary functions, which support that basic function. The purpose of functions maybe aesthetic or use, and basic functions maybe either or both of these. For example, a coat may have a use function of making you warm and an aesthetic function of' looking attractive'.

\section{WHEN TO APPLY VALUE ANALYSIS}

1.) New designs are being introduced.

2.) Rate of return on investment is reducing.

3.) Reduction in sales of the product manufactured by the company.

4.) Cost of manufacturing/tooling per unit is rising.

5.) Competitors' products are sold at comparatively cheaper rates.

\section{PURPOSE OF FUNCTIONAL ANALYSIS}

There are numerous purposes behind the Functional Analysis which can be seen through developing the Function Analysis Systems Technique (FAST) diagram

They are listed as follows:

1) Assuring proper relationships between functions.

2) Provides a good basis for classifying the functions.

3) Arrangement of the functions can help identify missing functions.

4) Clarification of the meaning of function can result from the diagramming of the functions.

5) Finding duplicate functions becomes more evident and marks those that may be eliminated or combined with others with the same result.

6) FAST can help avoid coming up with the right solution to the wrong problem. Thus expecting to possibly reduce the total cost of the products or services.

7) To set the scope of the project undertaking.

\section{ISSUES TO BE CHECKED FOR FUNCTIONAL ANALYSIS}
A. Function
B. Material Specification and Content
C. Material and Manufacturing
D. Standardization
E. Direct Labor Costs
F. Tolerances and Finishes
G. Costs of material

\section{FAST DIAGRAM}

One of the most popular and easiest ways of doing Functional Analysis is through developing the FAST diagram. FAST diagram is a technique that was developed to determine, classify and evaluate functions based on a function block diagram according to the how/why logic. The result is a hierarchy of functions in order of their importance as efforts to achieve a basic function, objective or end result. FAST can be divided into two types; technical FAST diagram and customer FAST diagram. Technical FAST diagram is used to understand the technical aspects of a specific portion of a total product while customer FAST diagram focuses on the aspects of a product that the customer cares about and does not delve into the technicalities, mechanics or physics of the product. Customer FAST diagram is usually applied to a total product.

The development of a FAST diagram helps teams to:

Develop a shared understanding of the project

$>$ Identify missing functions.

$>$ Define, simplify and clarify the problem.

$>$ Organize and understand the relationships between functions.

$>$ Identify the basic function of the project, process or product.

$>$ Improve communication and consensus.

$>$ Stimulate creativity.

\section{VAVE METHODOLOGY}

The four different segments of VAVE methodology used for this study was enhanced base on the Value Analysis Study Activity Chart (VASAC) which has covered the three out of seven phases from 
engineering design process; conceptual design, embodiment design and detail design. It is expected that the existing vehicle outer door handle especially for the 3-door hatchback car can be redesigned base on this methodology. The first two segments were covering the first phase of engineering design process.

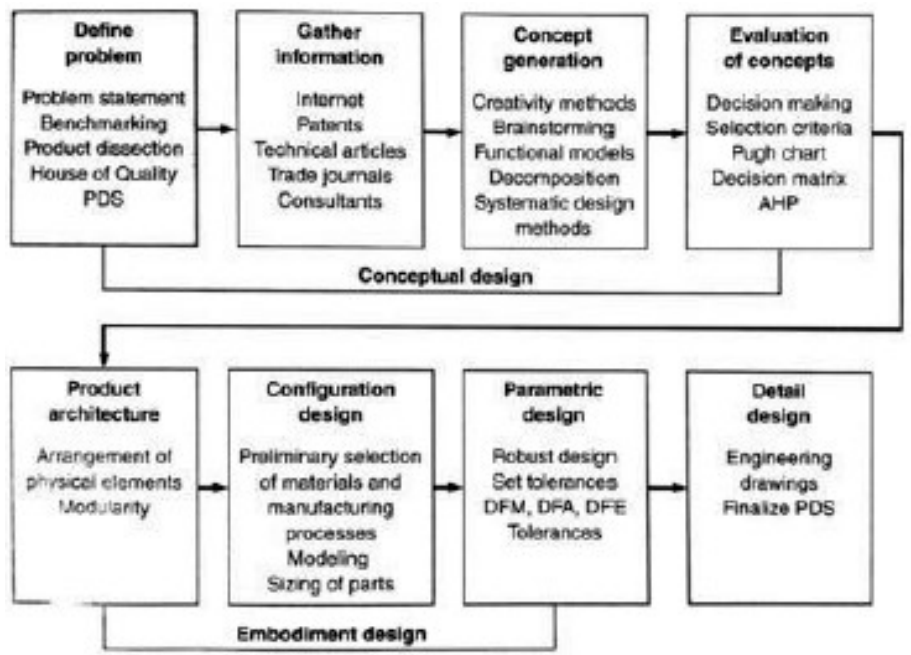

Figure-1. Discrete steps in engineering design process from problem definition to detail design. The chief tools or techniques applicable in each step are

\subsection{Preparation} given.

Data was collected through set of questionnaire done by the previous study regarding PROTON cars which has taken public as the respondents.

\subsection{Segment 1}

FAST diagrams were developed base on the function analysis made as to come out with a new target cost. Then, data may be collected from the benchmarking and observations for the new concept generation and selection. At the end of segment 1 , feasible design can be generated. However this case study only focuses up to the FAST diagram as to show how it can be developed and what are the benefits through this methodology.

\subsection{Segment 2}

Segment 2 is covering the next phase of engineering design process; embodiment design. From the feasible design generated in segment 1 , several alternatives can be introduced. These alternatives can be developed through modelling and prototyping. They may then been critiqued based on the Design for Manufacturing and Assembly (DFMA) guidelines as to come out with few feasible models.

\subsection{Segment 3}

Segment 3 is covering the detail design phase of engineering design process. The alternatives need to be further reviewed based on the cost. Current alternative designs cost need to be compared with the previous target cost in segment 1 . The final steps from Value Analysis need to be made before the alternatives can be resolved to select and propose for the best model. Selected best model may then be validated before the results can be presented and published.

PREPARATION $\longrightarrow$ SEGMINT $1 \longrightarrow$ SEGMIENT $2 \longrightarrow$ SEGMIENT 3

Figure-2. An overview of the VAVE methodology flowchart.

\section{CASE STUDY - VEHICLE OUTER DOOR HANDLE}

The company Perusahaan Otomobil Nasional (National Automotive Industry) PROTON is selected for the case study, located in Shah Alam, Selangor, Malaysia. Establish in 1983, PROTON is Malaysia's largest manufacturer of automobiles, and the only full -fledged OEM car manufacturer in Southeast Asia. Its key markets are from the United Kingdom to the Middle East and across South-East Asia and Australia - especially in countries like China, India and Iran PROTON produces cars to suit a range of customer demands and preferences. It offerings include versatile and reliable four-door family vehicles, twodoor hatchbacks for the young-at-heart, luxurious and stylish executive sedans, spacious and affordable multi- purpose vehicles, as well as the world renowned sports cars from Lotus. Most importantly, PROTON models are now developed with Lotus Engineering, offering customers a superior ride and handling experience, Hence, this study has applied the Functional Analysis tool to the product manufactured in this industry.

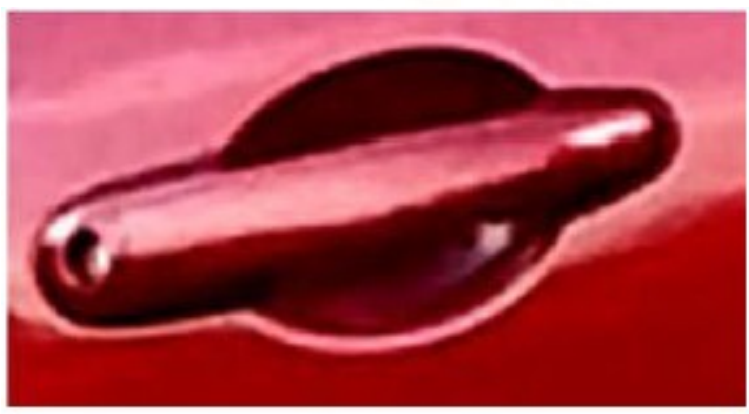

Figure-3. Current vehicle outer door handle. 
International Journal of Trend in Scientific Research and Development (IJTSRD) ISSN: 2456-6470

\subsection{Functional analysis worksheet}

Table-1. Functional analysis worksheet for the existed vehicle outer door handle.

\begin{tabular}{|c|c|c|c|c|c|c|c|}
\hline Part & Qty & \multicolumn{2}{|c|}{ Function } & \multicolumn{2}{|c|}{ Part } & \multicolumn{2}{|c|}{ Assembly } \\
\hline & & Verb & Noun & $*$ & $* *$ & $*$ & $* *$ \\
\hline Outside Handle & 1 & $\begin{array}{l}\text { Improve } \\
\text { Provide } \\
\text { Provide } \\
\text { Improve } \\
\text { Provide }\end{array}$ & $\begin{array}{l}\text { Appearance } \\
\text { Surface } \\
\text { Strength } \\
\text { Aesthetic } \\
\text { Protection }\end{array}$ & $X$ & $\begin{array}{l}X \\
X \\
X \\
X\end{array}$ & & \\
\hline Base Portion & 1 & $\begin{array}{l}\text { Provide } \\
\text { Provide } \\
\text { Hold } \\
\text { Support }\end{array}$ & $\begin{array}{l}\text { Movement } \\
\text { Strength } \\
\text { Assembly } \\
\text { Handle }\end{array}$ & $\begin{array}{l}X \\
X \\
X\end{array}$ & X & $\mathrm{X}$ & \\
\hline Grip Portion & 1 & $\begin{array}{l}\text { Facilitate } \\
\text { Open } \\
\text { Provide } \\
\text { Provide } \\
\text { Provide } \\
\text { Pull } \\
\text { Pull } \\
\text { Provide }\end{array}$ & $\begin{array}{l}\text { Working } \\
\text { Door } \\
\text { Grip } \\
\text { Surface } \\
\text { Strength } \\
\text { Door } \\
\text { Handle } \\
\text { Ergonomic }\end{array}$ & & $\begin{array}{l}X \\
X \\
X \\
X\end{array}$ & & \\
\hline Case Portion & 2 & $\begin{array}{l}\text { Hold } \\
\text { Provide } \\
\text { Provide } \\
\text { Provide } \\
\text { Provide } \\
\text { Support } \\
\text { Hold }\end{array}$ & $\begin{array}{l}\text { Assembly } \\
\text { Movement } \\
\text { Locking } \\
\text { Safety Cie } \\
\text { Strength } \\
\text { Handle an } \\
\text { Parts }\end{array}$ & $\begin{array}{l}\mathrm{X} \\
\mathrm{X} \\
0 \\
\mathrm{X}\end{array}$ & $\begin{array}{l}X \\
X\end{array}$ & $\mathrm{X}$ & \\
\hline Bell Crank & 1 & $\begin{array}{l}\text { Provide } \\
\text { Provide } \\
\text { Hold } \\
\text { Facilitate } \\
\text { Tug }\end{array}$ & $\begin{array}{l}\text { Movement } \\
\text { Strength } \\
\text { Assembly } \\
\text { Locking } \\
\text { Handle }\end{array}$ & & $\begin{array}{l}X \\
X\end{array}$ & $\mathrm{X}$ & \\
\hline Spring & 1 & $\begin{array}{l}\text { Provide } \\
\text { Hold } \\
\text { Provide }\end{array}$ & $\begin{array}{l}\text { Movement } \\
\text { Assembly } \\
\text { Stiffness }\end{array}$ & & $\begin{array}{l}\mathrm{X} \\
\mathrm{X}\end{array}$ & $\mathrm{X}$ & \\
\hline Pin & 1 & $\begin{array}{l}\text { Hold } \\
\text { Support }\end{array}$ & $\begin{array}{l}\text { Assembly } \\
\text { Local }\end{array}$ & $\mathrm{X}$ & $\mathrm{X}$ & $\mathrm{X}$ & \\
\hline Clip & 1 & $\begin{array}{l}\text { Hold } \\
\text { Provide } \\
\text { Provide } \\
\text { Hold }\end{array}$ & \begin{tabular}{|l} 
Rod \\
Movement \\
Strength \\
Assembly
\end{tabular} & $\begin{array}{l}X \\
X\end{array}$ & $\begin{array}{l}X \\
X\end{array}$ & $\mathrm{X}$ & \\
\hline Counter-weight & 1 & Support & Load & & $\mathrm{X}$ & & \\
\hline
\end{tabular}

Functional Analysis Worksheet of the existed vehicle outer door handle has been developed as in Table-1. This was the basis for the FAST diagrams development by which the basic (*) and secondary (**) functions of the part and assembly been ranked according to the particular 6.2. FAST diagram functions of each components. 


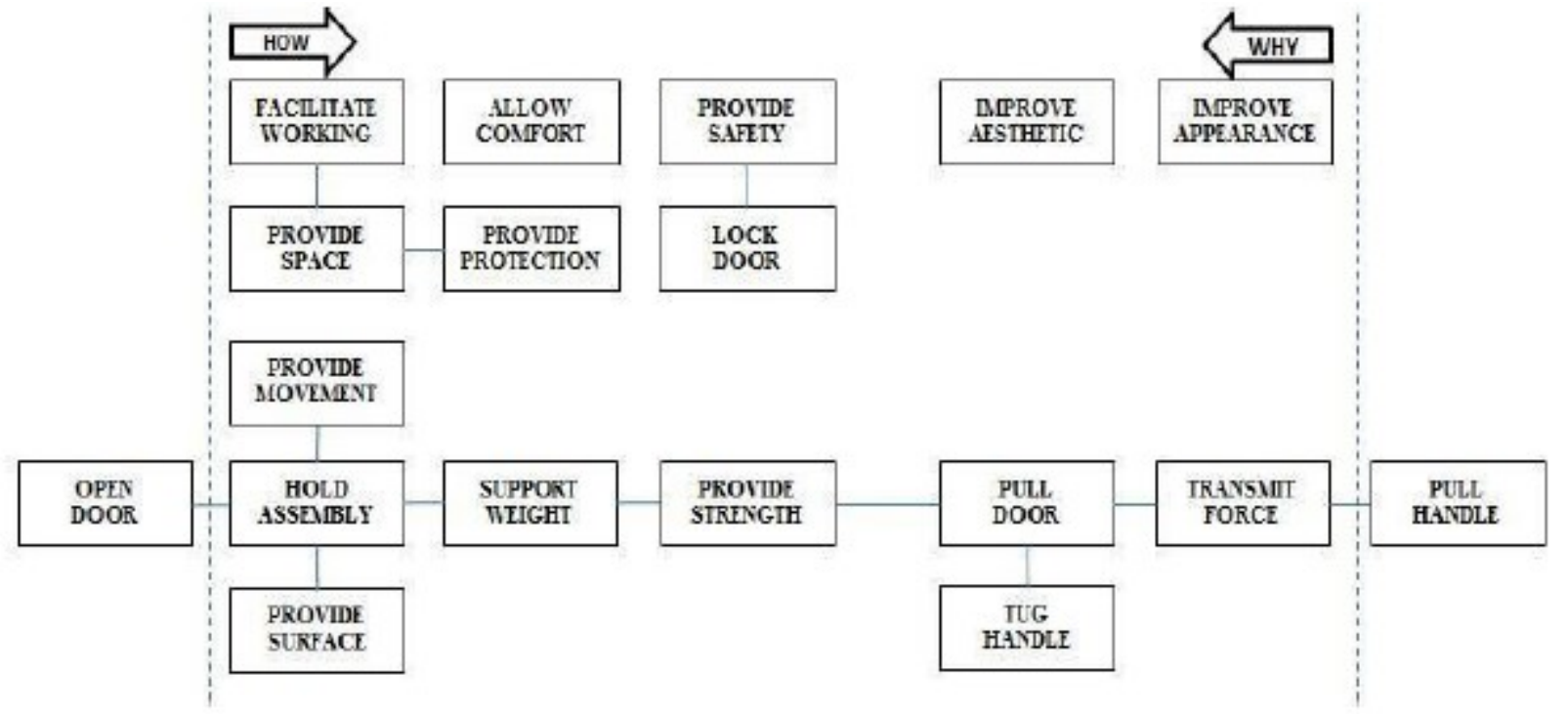

Figure-4. FAST diagram of the current outer door handle.

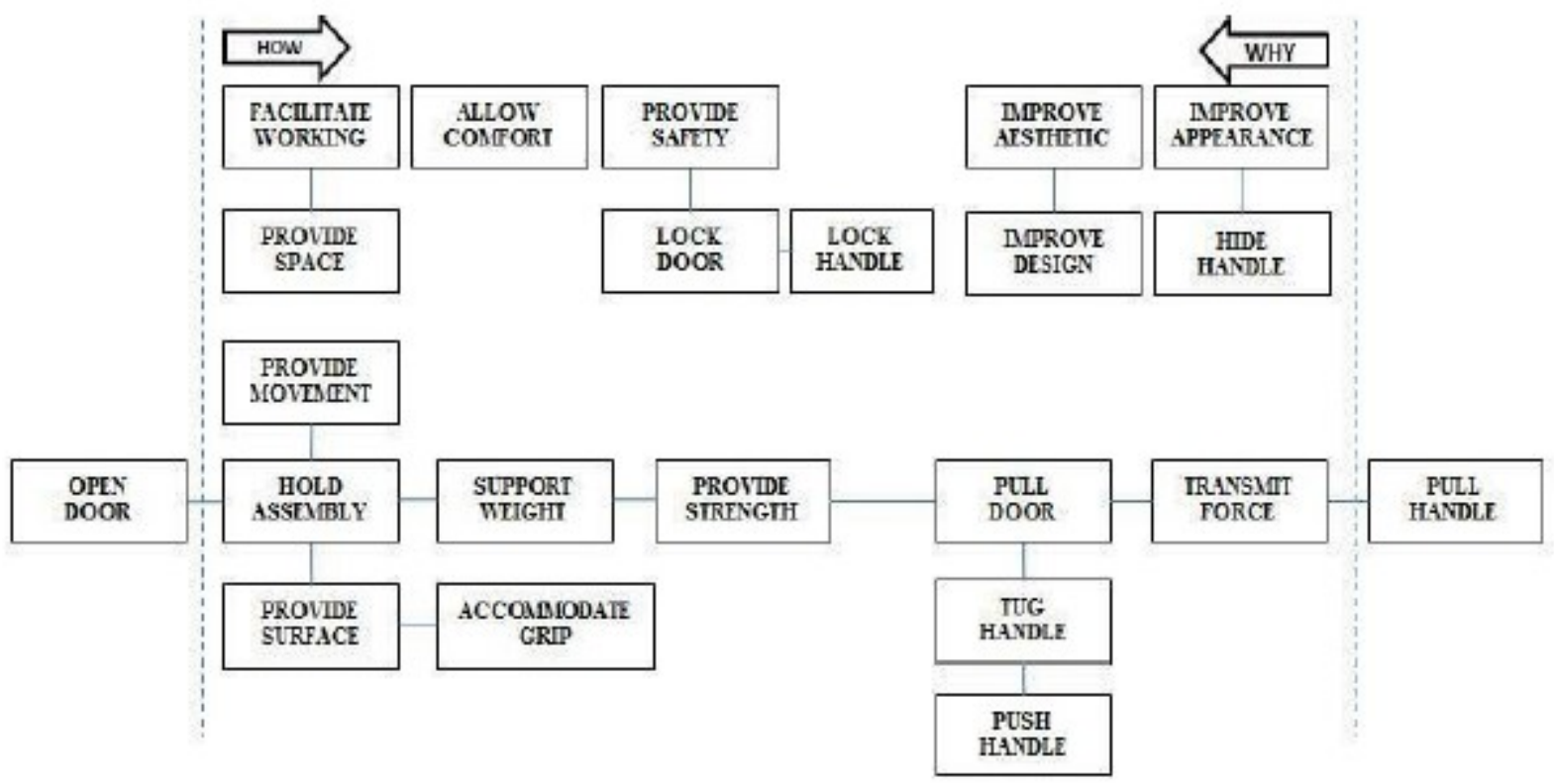

Figure-5. FAST diagram of the outer door handle proposed.

\section{CONCLUSION AND RECOMMENDATIONS}

In conclusion, Functional Analysis may be used to enhance product performance while maintaining its intended functions for solving particular problems without scarifying any project requirements for safety, quality, operations, maintenance or environment. FAST diagram applied shows the concept of concurrent engineering which give new opportunities for multidiscipline team to work together at the same time on the basic functions and to set the scope of the project undertaken. It allows the unlimited alternative ideas to be generated for the particular problem solutions within the scope lines, thus developing their potentials.
In the Case Study discussed above, Functional Analysis Worksheet of the existed vehicle outer door handle has been developed which shown in Table-1 as the basis for the FAST diagrams development. The basic and secondary functions of the part and assembly been ranked according to the particular functions for each components.

From the FAST diagram of the proposed idea, we can see that by scarifying one function in the existed model FAST diagram lead the study to have another five new different functions. This will eventually give us the opportunity in the future design to increase the value of the door handle to the customer by mean of functions to be increased while costs to be kept constant or reduced. In future, we can continue the validation analysis for any new design of the outer 
door handle using VAVE methodology so that the value of the said product can be enhanced.

\section{REFERENCES}

1) Viola N., Corpino S., Marco F., and Stesina F. 2012. Functional Analysis in Systems Engineering: Methodology and Applications, Systems Engineering - Practice and Theory, Prof. Boris Cogan (Ed.), ISBN: 978-953-51-0322-6, InTech, DOI: 10.5772/34556. Available from: http://www.intechopen.com/books/systemsengineering-practice-and-theory/functionalanalysis-in-systems-engineering-methodologyand-applications.

2) Dekker M. 2003. Value Engineering Analysis and Methodology. Available from: http://www.fcrm.ir/mads/ebk1085.pdf.

3) Annappa C. M. and Panditrao K. S. 2012. Improving Furniture Product through Value Engineering by Function Analysis Systems Technique (F.A.S.T). International Journal of Application or Innovation in Engineering and Management (IJAIEM), 1(4). Available from: http://www.ijaiem.org/volume1 Issue4/IJAIEM2012-12-10-007.pdf.

4) Project Development Procedures Manual (PDPM). 2014. Retrieved May 20, 2014, from http://www.dot.ca.gov/hq/oppd/pdpm/pdpmn.htm.

5) Dieter G. E. and Schmidt L. C. 2008. Engineering Design. 5th Edn., New York: Mc Graw Hill.

6) Jasin A. K. and Sooi C. C. 2010. A Saga Proton's 25-Year Story. Malaysia: Berita Publishing. 